\title{
PARENTAL SATISFACTION WITH PEDIATRIC POSTERIOR PREFORMED ZIRCONIA AND STAINLESS STEEL CROWNS- A COMPARATIVE STUDY
}

\author{
Dr. Gayathri Murali*, Dr. Jayanthi Mungara, Dr. Nilaya Reddy Venumbaka, \\ Dr.Sai Sarath kumar Kothimbakkam, Dr.Santhosh Priya. A.K.R \\ Department of Pedodontics and Preventive Dentistry, \\ *SRM Kattankulathur Dental College and Hospital, Tamilnadu, India. \\ Ragas Dental College and Hospital, Chennai, Tamilnadu, India.
}

\section{To access \& cite this article}

Website: jidam.idamadras.com

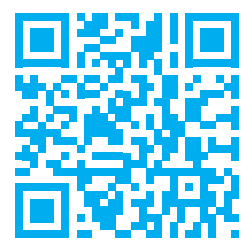

DOI:10.37841/jidam_2020_V7_I2_02

\section{Address for correspondence:}

Dr.Gayathri Murali, MDS,

3e,Saravana Apartment,

240,St.Marys Road, Mandaveli,

Chennai-600028

Email id: drgayathrimurali1992@gmail.com

\section{ABSTRACT}

AIM: To elicit parental acceptance and satisfaction with pediatric preformed Stainless Steel Crown(SSC) and zirconia crowns in posterior primary teeth.

METHODOLOGY: Parental satisfaction was elicited from 25 parents with a 5-point likert type questionnaire. Problems experienced by the child and future treatment recommendations were also elicited with close ended questions during the followup visit after 12 months from the time of treatment.

RESULTS: Overall parental satisfaction was $78 \%$ with stainless steel crowns and $96 \%$ with zirconia crowns. $8 \%$ of the parents reported bleeding around the gums in zirconia group. $60 \%$ of the parents in stainless steel crown group and $100 \%$ of zirconia crown group reported that they would opt for these crowns in future.

CONCLUSION: Preformed zirconia crowns can be an option for posterior full coronal restoration when esthetics is of prime concern for the parent and child.

KEY WORDS: Zirconia crowns, Stainless steel crowns, Parental satisfaction.

\footnotetext{
Received : : 18.05.2020

Accepted : :05.06.2020

Published : :27.06.2020
} 


\section{INTRODUCTION:}

Early childhood caries is a complex disease affecting the primary teeth for which parents often seek treatment. The management often includes alleviation of infection and reestablishment of form and function using full coronal restorations. Stainless steel crowns(SSC) were the choice of full coronal restoration, as they were easily available as pre-formed, pre-trimmed and pre-contoured crowns with wide range of sizes and with proven clinical efficiency. The only disadvantage of SSC was its unaesthetic appearance. . $^{1,2,3}$

A survey of pediatric dentists reported that $87 \%$ of the parents are concerned about the esthetics of even posterior restorations. In addition, studies suggest that even children are more concerned about esthetics as it influences their psychological well being and physical appearance. ${ }^{4,5}$

The need to meet the demand for esthetic restorations led to the introduction of open faced stainless steel crowns, preveneered crowns, polycarboxylate crowns and strip crowns. Each of these full coronal restorations has their own advantage and disadvantage. Initially preveneered stainless steel crowns showed short term success rate, but long term follow-up studies have reported frequent fracture of these crowns as a whole or a part of it. $^{6,7,8}$

The technological advances in techniques and material science led to the evolution of preformed zirconia crowns for primary teeth, so as to fulfill the esthetic demands, at the same time promise good durability. Zirconia crowns are known as "Ceramic Steel" as it provides strength close to available metal crowns as well as colour similar to that of natural teeth. Pediatric zirconia crowns were introduced by EZ-pedo and became commercially available in 2008. Later preformed zirconia crowns were popularized by companies like Nusmile, Kinderkrowns, Cheng crowns, Signature crowns and many more. These preformed crowns differed with respect to size, shape, shade and pattern of retention component. ${ }^{9}$ Advantages of preformed zirconia crowns are its esthetics, full coverage of the treated tooth, no component of the crown that might debond and potentially less technique sensitive when compared to other esthetic alternatives. The potential disadvantages include, need for more tooth reduction ${ }^{10}$, inability to crimp or contour the crown and they are also expensive.

It has been observed that impact of esthetics plays an important role even in posterior primary teeth. Zirconia crowns are by far the strongest dental ceramic restoration available as preformed posterior esthetic crowns for primary dentition and very limited literature is available with regards to its efficiency and parental acceptance. Thus this study was carried out to assess and elicit parental satisfaction for preformed posterior zirconia crowns and stainless steel crowns.

\section{METHODOLOGY:}

Parental satisfaction was elicited after placement of the crown in primary molars of 25 children post pulp therapy (Fig 1,2,3). Parental satisfaction was elicited with regards to the size, shape, colour, durability and overall satisfaction, impact on oral health and appearance. It was assessed with 5-point likert type questionnaire where '1-Very dissatisfied, 2-Dissatisfied, 3-Neutral, 4-Satisfied and 5-Very satisfied'. The problems encountered by the children such as bleeding around crown, sensitivity and food lodgement and future treatment options were evaluated with 'Yes/No' dichotomous questions.

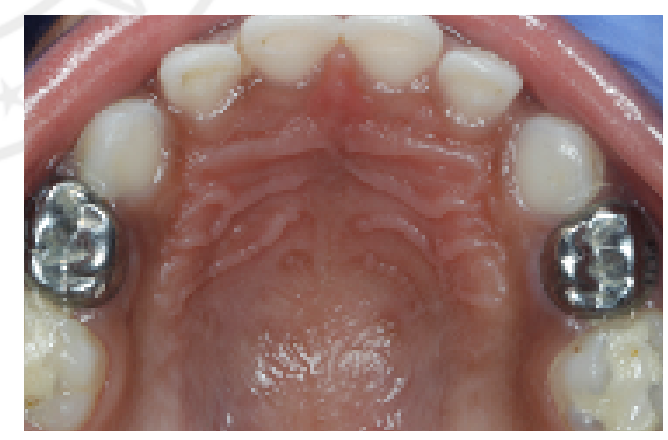

Fig 1: Post Operative Photograph of Maxilla

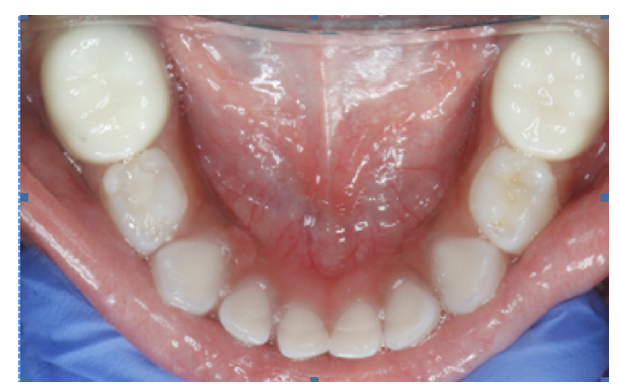

Fig 2: Post Operative Photograph of Mandible 


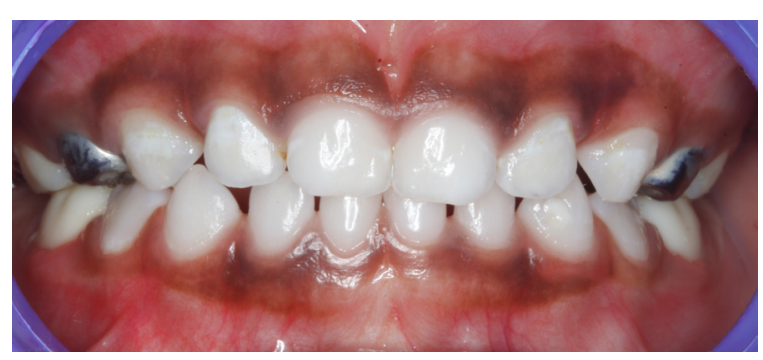

Fig 3:In Occlusion

\section{RESULT:}

Parental satisfaction with durability was similar in both the groups $(100 \%) .60 \%$ of them were satisfied with the size and shape of stainless steel crowns and only $13 \%$ were satisfied with the colour of it. $100 \%$ satisfaction with shape and colour of zirconia crown was noted while only $87 \%$ were satisfied with the size of the crown.(Graph $1 \& 2$ ).

Majority of the parents in both the groups (78\% SSCs and 96\% zirconia crowns) were satisfied with the crowns. Mild bleeding (8\%) was reported in zirconia group whereas no such complaints were reported with stainless steel crowns. Parents were ready to recommend both the crowns with preference for zirconia crowns $(100 \%$ for zirconia crown and $60 \%$ for stainless steel) because of its colour being similar to that of natural teeth (Graph - 3).

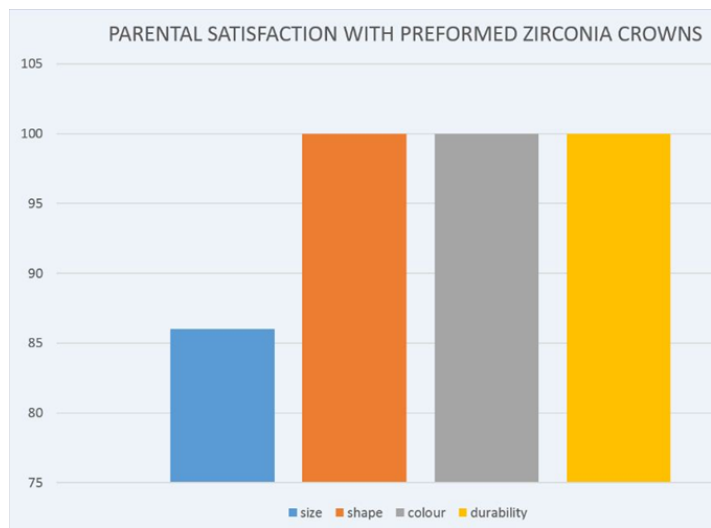

Graph 1: Parental Satisfaction With Preformed Zirconia Crowns

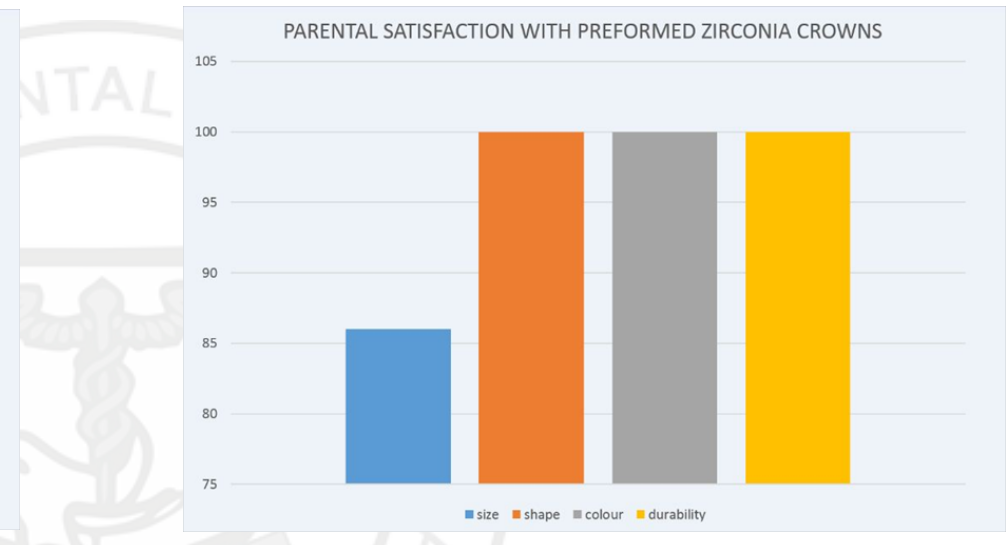

Graph 2: Parental Satisfaction With Stainless Steel Crowns

\section{FUTURE TREATMENT CHOICE}

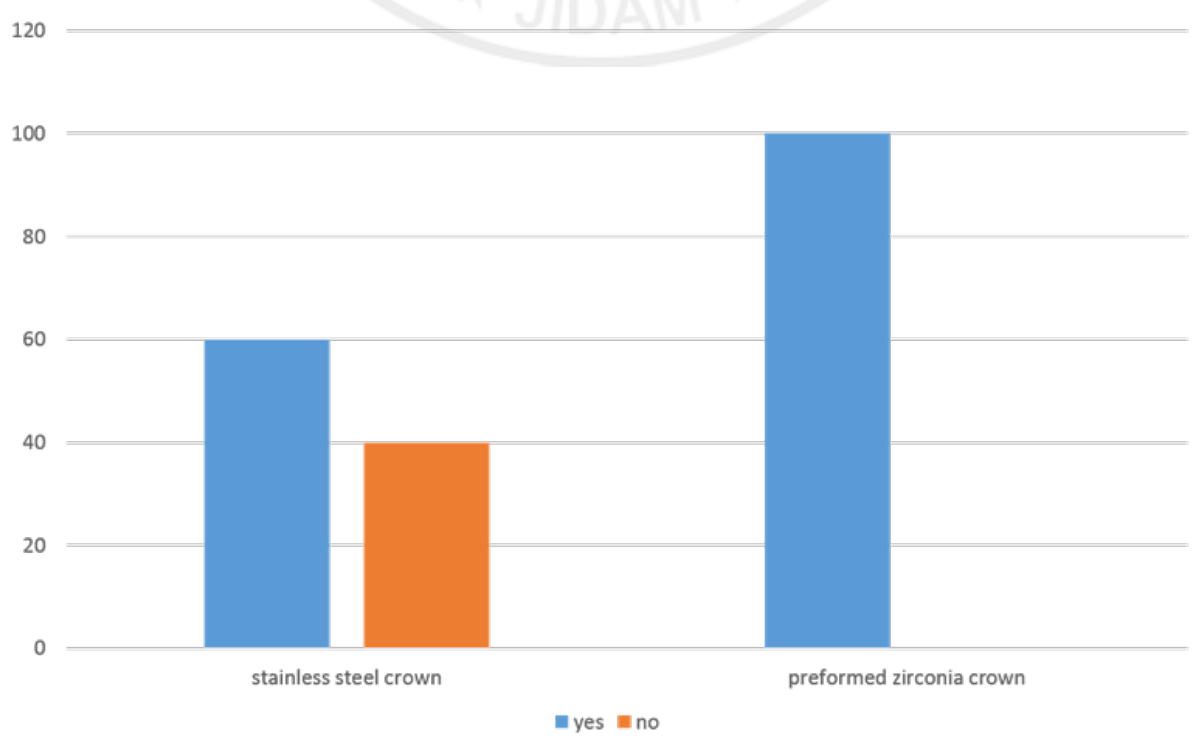

Graph 3: Future Treatment Option 


\section{PARENTAL SATISFACTION:}

\begin{tabular}{|l|}
\hline Category \\
\hline 1. Size \\
\hline 2. Shape \\
\hline 3. Colour \\
\hline 4.Durability \\
\hline 5.Overall satisfaction \\
\hline Scoring criteria \\
\hline Score 1 - Very Dissatisfied \\
\hline Score 2 - Dissatisfied \\
\hline Score 3 - Neutral \\
\hline Score 4 - Satisfied \\
\hline Score 5 - Very Satisfied \\
\hline
\end{tabular}

PROBLEMS EXPERIENCED BY THE CHILD:

\begin{tabular}{|ll|}
\hline Category & \\
\hline 1.Bleeding around crown & - YES / NO \\
\hline 2.Sensitivity & - YES / NO \\
\hline 3.Food lodgment & - YES / NO \\
\hline
\end{tabular}

\section{FUTURE TREATMENT CHOICE:}

\begin{tabular}{|l|l|l|}
\hline Category & $\begin{array}{l}\text { Stainless steel } \\
\text { crown }- \\
\text { YES / NO }\end{array}$ & $\begin{array}{l}\text { Zirconia crown - } \\
\text { YES / NO }\end{array}$ \\
\hline
\end{tabular}

\section{DISCUSSION:}

Full coronal restorations have become the prevalent part of rehabilitation of the children affected with early childhood caries. Multiple options have been tried with each one showing varied clinical performance. Change in lifestyle, more opportunities to socialize and role of media plays a role in exposing the children to a concept of ideal beauty at very young age. This has showed impact on their concerns about esthetics which is similar to that of adults. ${ }^{4}$ The same principle applies in terms of restorations to be placed on their teeth. ${ }^{5}$
With the concept of esthetics gaining interest among parents and children, preformed zirconia crowns are becoming much more popular. ${ }^{11}$ But very limited literature is available regarding their performance. Keeping the above fact in mind, the present study was conducted to elicit parental satisfaction of pediatric zirconia crowns with that of stainless steel crowns which were the most commonly used crowns for posterior primary teeth. ${ }^{1,12}$

The parental satisfaction of the crowns were obtained through a survey with a set of dichomotous 'Yes/No' questions and 5 point likert type scale adopted from other studies. ${ }^{8,13,14}$

In this study, preformed Kinderkrowns were used due to the availability of varied sizes, better retentive features and a polished surface to reduce opposing tooth wear. According to themanufacturer's guidelines, resin modified glass ionomer (3M ESPE Rely X) was used to lute the crowns. Preformed SSC were luted with type 1 GIC (GC Type 1 GIC) as it is the most commonly recommended cement for luting stainless steel crowns. ${ }^{15}$

Parental satisfaction obtained with a 5-point likert scale and an 'Yes/No' questionnaire revealed good satisfaction with respect to size and shape of both the crowns with better results with zirconia crowns (4.8 Mean score). The values were slightly higher than the findings of Holsinger et al (4.4). ${ }^{11}$ With respect to colour, zirconia outperformed stainless steel (2.9) with a mean score of 5. Both zirconia and stainless steel crowns performed similar with respect to parents' perception of durability with a mean score of 4.8 which was slightly higher than the values obtained by Walia et al (4.7).${ }^{16}$ Overall satisfaction with zirconia crown (4.8) was better than the stainless steel crowns (4.2). Impact of both the crowns on oral health and appearance (4.8) were slightly higher than the results of Holsinger et al (4.7). ${ }^{11}$ Problems experienced by children after the crowns were none, except for $8 \%$ of the zirconia crowns who reported bleeding around the crowns. Overall plaque accumulation could be attributed as the reason for poor gingival health as an improvement was noted with oral prophylaxis and oral health education.

All the parents were ready to opt for zirconia crowns $(100 \%)$, whereas only $60 \%$ accepted to opt for stainless steel crowns. Most of the parents were 
satisfied with stainless steel crowns only in maxillary dentition, but with respect to mandibular molars they preferred esthetic zirconia crowns.

Further studies are recommended following a split-mouth design, testing different brands of commercially available zirconia crowns with varied level of polish, gloss and morphological variations for a longer duration to get more valuable information on the clinical performance of preformed zirconia crowns.

\section{CONCLUSION:}

Both stainless steel crowns and zirconia crowns are an excellent option for restoration of posterior primary teeth. But zirconia crowns can be the choice of post-endodontic restoration when esthetics is of prime concern for the parents.

\section{FINANCIAL SUPPORT AND SPONSORSHIP:}

Nil

\section{CONFLICTS OF INTEREST:}

There are no conflicts of interest.

\section{REFERENCES:}

1. Messer LB, Levering NJ. The durability of primary molar restorations: II. Observations and predictions of success of stainless steel crowns. Pediatr Dent 1988 Jun;10(2):81-5.

2. Clinical AC, American Academy of Pediatric Dentistry. Guideline on pediatric restorative dentistry. Pediatric dentistry 2012;34(5):173.

3. Abdulhadi BS, Abdullah MM, Alaki SM, Alamoudi NM, Attar MH. Clinical evaluation between zirconia crowns and stainless steel crowns in primary molar teeth. Journal of Pediatric Dentistry 2017 Jan 1;5(1):21.

4. Pani SC, Saffan AA, AlHobail S, Bin Salem F, AlFuraih A, AlTamimi M. Esthetic concerns and acceptability of treatment modalities in primary teeth: a comparison between children and their parents. International journal of dentistry. 2016
5. Fishman R, Guelmann M, Bimstein E. Children's selection of posterior restorative materials. Journal of Clinical Pediatric Dentistry 2007 Sep;31(1):1-4.

6. Fuks AB, Ram D, Eidelman E. Clinical performance of esthetic posterior crowns in primary molars: a pilot study. Pediatric dentistry 1999;21(7):445-8.

7. Ram D, Fuks AB, Eidelman E. Long-term clinical performance of esthetic primary molar crowns. Pediatric Dentistry 2003 Nov $1 ; 25(6)$.

8. Roberts C, Lee JY, Wright JT. Clinical evaluation of and parental satisfaction with resin-faced stainless steel crowns. Pediatric Dentistry 2001 Jan;23(1):28-31.

9. Tote J, Gadhane A, Das G, Soni S, Jaiswal $\mathrm{K}$, Vidhale G. Posterior esthetic crowns in Peadiatric Dentistry. Int J Dent Med Res 2015;1(6):197-201.

10. Clark L, Wells MH, Harris EF, Lou J. Comparison of amount of primary tooth reduction required for anterior and posterior zirconia and stainless steel crowns. Pediatric dentistry 2016 Feb 15;38(1):42-6.

11. Holsinger DM, Wells MH, Scarbecz M, Donaldson M. Clinical evaluation and parental satisfaction with pediatric zirconia anterior crowns. Pediatric dentistry 2016 Jun 15;38(3):192-7.

12. Hickel RE, Kaaden C, Paschos EK, Buerkle V, García-Godoy F, Manhart J. Longevity of occlusally-stressed restorations in posterior primary teeth. American Journal of Dentistry. 2005 Jun 1;18(3):198.

13. Shah PV, Lee JY, Wright JT. Clinical success and parental satisfaction with anterior preveneered primary stainless steel crowns. Pediatric Dentistry 2004 Sep;26(5):391-5.

14. Salami A, Walia T, Bashiri R. Comparison of parental satisfaction with three tooth-colored full-coronal restorations in primary maxillary incisors. Journal of Clinical Pediatric Dentistry 2015 Sep;39(5):423-8.

15. Croll TP, Nicholson JW. Glass ionomer cements in pediatric dentistry: review of 
the literature. Pediatric dentistry 2002 Sep;24(5):423-9.

16. Walia T, Salami AA, Bashiri R, Hamoodi OM, Rashid F. A randomised controlled trial of three aesthetic full-coronal restorations in primary maxillary teeth. Eur J Paediatr Dent2014 Jun;15(2):113-8. 